\title{
Students' reasons for STEM choices and the relationship of mathematics choice to university admission
}

\author{
Satu Kaleva* (D), Jouni Pursiainen, Mirkka Hakola, Jarmo Rusanen and Hanni Muukkonen
}

\begin{abstract}
Background: Despite the increasing need for STEM skills, to date, the connection between STEM subject choices and their impact on students' educational pathways has not been widely studied. Focusing on the mathematics choice (basic/advanced/no mathematics), a large register dataset that covered students admitted to Finnish universities during 2013-2015 ( $N=46,281)$ was combined with upper-secondary school matriculation examination data $(N=93,955)$ to find out how this choice influenced the students' university admissions. This large dataset was also examined to establish the current gender distributions in different university degree programs from the perspective of mathematics choices. Further, to find out the students' reasons behind their mathematics choices, a cohort sample of 802 student responses was collected from upper-secondary schools. We also investigated the students' interests in different fields of study to establish any gender differences in them.

Results: The register data analysis suggested that in Finland, students' mathematics choices had a strong influence on the university admission outcomes. For instance, only $33 \%$ of the upper-secondary school graduates took the advanced mathematics ME test in 2013-2015, yet the number of those admitted to universities who had taken the advanced mathematics ME test was 55\%. Most of the university degree programs were female dominated, yet the university students with advanced mathematics were mostly male, and especially the STEM fields in the Finnish universities were male dominated. As for the reasons behind the mathematics choices, students who chose advanced mathematics believed in its usefulness for their future studies and careers. We also found significant gender-based educational differences regarding all the study fields, with STEM careers attracting more males than females.

Conclusion: Advanced mathematics was highly valued in Finnish universities, and many students chose advanced mathematics believing in its usefulness for their future studies or careers. Yet, their further study interests and career plans were segregated by gender. As there is a rising need for STEM skills, we must seek effective ways to deliver the evolving possibilities of STEM fields to students, especially girls, during the earlier years of their educations.
\end{abstract}

Keywords: Upper-secondary school students' mathematical choice, STEM subjects, STEM fields, STEM careers, Gender segregation in disciplines, Mathematics choice, University admissions, Gender gap in STEM

\section{Introduction}

Reasons for the gender gap in STEM (science, technology, engineering, and mathematic) fields have been sought in several studies (e.g., Allen \& Eisenhart, 2017; Chow, Eccles, \& Salmela-Aro, 2012; Perez, Cromley, \& Kaplan, 2014). In the USA, Wang and Degol (2016) found six explanations for women's underrepresentation in STEM fields: (a) cognitive ability, (b) relative cognitive

\footnotetext{
*Correspondence: satu.kaleva@oulu.fi

Faculty of Education, University of Oulu, Fl-90014 Oulu, Finland
}

strengths, (c) occupational interests or preferences, (d) lifestyle values or work/family balance preferences, (e) field-specific ability beliefs, and (f) gender-related stereotypes and biases. As the size and composition of the STEM workforce continuously fails to meet the demand (Jang 2016; Wang \& Degol, 2016), it is important to understand the barriers and factors that influence individual education and career choices (Blotnicky, FranzOdendaal, French \& Joy, 2018).

Individual differences in self-efficacy beliefs can impact career choices. Social cognitive career theory (SCCT) 
suggests that career interest, choice, and personal goals form a complex human agency process that includes performance, self-efficacy, and outcome expectations (Bandura, 1986; Lent, Brown, \& Hackett, 1994). Further, Wang, Eccles, and Kenny (2013) suggested that the pattern of gender differences in math and verbal ability may result in females having a wider choice of careers in both STEM and non-STEM fields compared with males. Thus, mathematically capable individuals, who also had high verbal skills, were less likely to pursue STEM careers than individuals who had high math skills but moderate verbal skills. Wang et al. (2013) found that that the group with high math skills and high verbal ability included more females than males. Their study provided evidence that it is not a lack of ability that causes women to pursue non-STEM careers but rather the greater likelihood that females with high math ability also had high verbal ability and thus could consider a wider range of occupations than their male peers with high math ability who were more likely to have moderate verbal ability.

Students with higher mathematics self-efficacy and STEM career knowledge are more likely to choose a STEM career (Blotnicky et al. 2018; Wang et al. 2013). In addition, students' own beliefs that success in science depends on exceptional talent can negatively impact their motivation to learn as well as a lack of enjoyment and confidence (Lin-Siegler, Ahn, Chen, Fang, \& LunaLucero, 2016; Wu, Deshler, \& Fuller, 2018). Without encouragement or adequate knowledge about the educational and career opportunities that STEM skills enhance, there is a risk that students will dismiss a STEM-based career path as a potential option for their future (Blotnicky et al. 2018). Although the gender gap in studying STEM subjects (e.g., number of courses taken and performance in those courses) has narrowed in recent decades (Välijärvi \& Sulkunen, 2016; Wang \& Degol, 2013), females continue to be less likely to pursue STEM careers than their male counterparts (Ceci \& Williams, 2007; Hübner, Wille, Cambria, Oschatz, Nagengast, \& Trautwein, 2017; Stage \& Maple, 1996).

This study deals with these internationally recognized challenges to find out how subject choices influence later educational paths and careers and how 16- and 17-yearold students in the Oulu area define their own choices in terms of STEM subjects, study plans, and careers. Finland has an outstanding digital infrastructure, and its ICT sector is bigger than that of its European peers (European Commission, 2019). Especially in the Oulu area, the ICT sector has only existed for about 30 years but has grown quickly, providing an increasing number of career opportunities particularly for those with STEM competencies.

In Finland, the importance of upper-secondary school subject choices is currently increasing, as student selection to the universities will be more heavily based on the results of the matriculation examination in the future. By understanding the reasons behind those choices, we can discover the existing gaps in our education system and develop ways for education to assist youngsters in seeing the new, growing STEM opportunities and to meet the demands of the future.

\section{Gender gap in studying STEM narrows, yet remains in STEM work fields}

Dasgupta and Stout (2014) investigated why the shortage of women in STEM careers remains stark. Their research points to different obstacles particularly relating to three developmental periods: (a) childhood and adolescence, (b) emerging adulthood, and (c) young-tomiddle adulthood. In their article, Dasgupta and Stout describe how specific learning environments, peer relations, and family characteristics become obstacles to STEM interest, achievement, and persistence in each period. They discovered some key obstacles: (1) in childhood and adolescence, masculine stereotypes about STEM, parents' expectations of daughters, peer norms, and a lack of fit with personal goals make girls move away from STEM fields; (2) in emerging adulthood, feeling like a misfit in STEM classes, being vastly outnumbered by male peers, and lacking female role models make women avoid STEM majors or leave prematurely; and (3) in early to mid-adulthood, subtle gender bias in hiring and promotion, biased evaluation of scientific work, non-inclusive department climates, juggling work/ family responsibilities, and difficulty returning after a family-related pause undermine the retention of women in STEM. To remove these obstacles, Dasgupta and Stout (2014) recommend evidence-based programs and policies be implemented during each of these developmental periods.

The scale and variability of gender differences in vocational interests have been examined, e.g., by Holland's (1997) RIASEC (realistic, investigative, artistic, social, enterprising, and conventional) theory of careers that explain what personal and environmental characteristics lead to satisfying career decisions, what personal and environmental characteristics lead to stability and change in the kind and level of work a person performs over time, and what are the most effective methods for providing assistance to people with career problems. His theory allows us to predict the outcome of personenvironment interactions and provides explanations for those previous fundamental questions (Holland, 1997). $\mathrm{Su}$, Rounds, and Armstrong (2009) studied vocational interests and suggest that men prefer working with things and women prefer working with people. Indeed, to be engaged in studying STEM subjects, students need to have high levels of interest, skills, and desire for 
challenges (Wang \& Degol, 2017, Linnansaari et al., 2015). Students' situational interest in science lessons is not as uniform as in other lessons, and Linnansaari et al. (2015) suggest that girls tended to be interested in life science lessons and uninterested in physical science lessons, and in contrast, boys are highly interested in physical science topics but not life sciences. For example, in previous studies, physics was considered uninteresting because it was considered as difficult, irrelevant, and boring by some students, especially girls (Williams, Stanisstrect, Spall, Boyes, \& Dickson, 2003).

Science and STEM identity has a complex differential function in supporting students' optional science choices by gender, and STEM identity may be associated with academic performance and flourishing in undergraduate physics courses at the end of the term, particularly for women (Seyranian et al., 2018; Vincent-Ruz \& Schunn, 2018). In mathematical problem solving, the role of selfefficacy beliefs and the nature of science identity has also been widely investigated (Pajares \& Miller, 1994; Pajares \& Urdan, 2006; Vincent-Ruz \& Schunn 2018; Zeldin \& Pajares, 2000). In their longitudinal study, Parker, Marsh, Ciarrochi, Marshall, and Abduljabbar (2014) found (a) a strong relationship between achievement, self-efficacy, and self-concept in mathematics at age 15; (b) both selfconcept and self-efficacy being independent and similarly strong predictors of tertiary entrance ranks at the end of high school; (c) math self-efficacy as a significant predictor of university entry but math self-concept was not; and (d) math self-concept as a significant predictor of undertaking post-school studies in science, technology, engineering, or math, but math self-efficacy was not.

The impact of teaching STEM subjects has been studied, e.g., by Bottia, Stearns, Mickelson, Moller, and Valentino (2015). They suggest that although the proportion of female math and science teachers at school had no impact on male students, it had a powerful effect on female students' likelihood of declaring and graduating with a STEM degree, and the effects were largest for female students with the highest math skills (Bottia et al., 2015).

\section{Factors impacting students' decisions in subject selection}

There are many factors that have an impact on the subject choices that students make. Palmer, Burke, and Aubusson (2017) used a best-worst scaling (BWS) survey to investigate the relative importance of factors thought to impact students' subject selection decisions. According to their findings, students ranked enjoyment, interest and ability, and perceived need in their future study or career plans as the most important factors in both choosing and rejecting subjects. They considered advice from teachers, parents, or peers to be relatively less important. According to several studies, enhancing students' enjoyment, interest, and perceptions of their ability in science, and their attitude towards it, as well as increasing student perceptions of the value of science in a future career may result in more students studying science at school (Osborne, Simon, \& Collins, 2003; Palmer et al., 2017).

Another important issue is the quality of STEM education where the teacher's role is essential. Slavit, Nelson, and Lesseig (2016) suggest that a teacher's role is a complex mixture of learner, risk-taker, inquirer, curriculum designer, negotiator, collaborator, and teacher. It is important to understand teachers' own beliefs and perceptions related to STEM talent development. According to Margot and Kettler (2019), teachers with increased confidence in teaching STEM would likely be more effective at integrating STEM activities, and increased confidence leads to better performance during instruction, which leads to gains in student learning.

\section{Case Finland}

The Program for International Student Assessments (PISA) conducted by the Organization for Economic Cooperation and Development (OECD) has kept Finland among the highest-ranking countries in the world in education since 2001. However, recent PISA scores present an ambivalent message. On the one hand, Finland is still a top-ranking country in education. On the other, a decrease in learning outcomes, observed for more than 10 years, has leveled off in reading literacy and slowed down in mathematical literacy but still remains a concern. These concerns extend to the future of basic education, as the average trend in all three domains has been declining since 2009 (Välijärvi \& Sulkunen, 2016). The PISA 2015 survey showed that the number of poor performers in science was growing, and the number of top performers was declining in Finland, especially among boys, and that regional equity was deteriorating. The number of Finnish students who performed poorly in science had nearly tripled, and the number of top performers had dropped by nearly one third. Altogether, 65 percent of the students who performed poorly in science also did poorly in mathematics and reading. Of these, two thirds were boys (Ministry of Education and Culture, 2016).

According to the new government program in Finland, a national goal is to increase the number of highly educated people in the youth population to reach more than 50\% (Finnish Government, 2019). Higher STEM identification may be associated with higher academic achievement (Seyranian et al., 2018), yet STEM subjects or fields such as ICT (Castaño \& Webster 2011) are not attracting enough students, and the decreasing number 
of students in science learning has been recognized as a national problem (Linnansaari, Viljaranta, Lavonen, Schneider, \& Salmela-Aro, 2015). Finland provides many career opportunities especially for people with STEM competencies. As an example, in 2014, The World Economic Forum in their Global Information Technology Report (GITR) ranked Finland as number one for its outstanding digital infrastructure for the second consecutive year (Bilbao-Osorio, Dutta, \& Lanvin, 2014). The successes in the digital fields were largely based on STEM competencies, but as in many other countries, Finland is barely getting enough students with sufficient skills in mathematics and science.

\section{Current study}

\section{Research questions}

To determine how mathematics choice related to the students' university admissions, we combined two large national datasets. Based on the combined register dataset, we examined:

1) How students' mathematics choices related to the university admissions and to the student distribution in different degree programs?

2) From the perspective of mathematics choices, what was the gender distribution among bachelor's degree graduates in different degree programs?

Based on a cohort sample of one city's first-year upper-secondary school students' responses, we also investigated:

3) What were the reasons that students chose basic or advanced mathematics during the first year of their studies?

4) Which further study fields were students interested in during the first year of their upper-secondary school studies and what gender-based differences were found in the interest?

\section{Methods}

\section{Setting of the study: education system in Finland}

In Finland, there are 5.5 million inhabitants, of which 2.8 million are female. Approximately 2 million are wage and salary earners, and 1.3 million children and youngsters are students. The number of high educational qualifications achieved in 2015 from universities of applied science was 26,175 and from research universities was 32,718 degrees (Statistics Finland, 2017). Education is free of charge for all, providing an equal basis for education. The Finnish education system consists of:

1) Early childhood education and care before compulsory education begins.
2) Pre-primary education for children in the year preceding the beginning of compulsory education.

3) Nine-year compulsory basic education (comprehensive school).

4) Upper-secondary education (general uppersecondary education or vocational education).

5) Higher education (universities or universities of applied sciences).

6) Furthermore, adult education is available at all levels. (Ministry of Education and Culture 2017; Finnish Ministry of Education and Culture 2017).

\section{General upper-secondary education}

After the 9-year compulsory basic education, schoolleavers opt for general or vocational upper-secondary education. Both forms usually take 3 years and provide eligibility for higher education. More than 90 percent of the relevant age group starts general or vocational uppersecondary studies immediately after basic education. There are no national tests in the basic education stage (ages 715), and if students decide to continue their studies in upper-secondary education, a national examination, the Matriculation Examination (ME), takes place at the end of their studies (age 19). The tests are assessed first by the upper-secondary school teachers and then by assessors, who are members or associate members of the Matriculation Examination Board. Every year, approximately 30,000 candidates take the exam, with $6 \%$ of the candidates failing the exam. The examination consists of four compulsory tests and additional optional tests. The compulsory tests are the candidate's mother tongue, together with three other tests selected from four options, which are the second national language (advanced/intermediate level), a foreign language (advanced/basic level), mathematics (advanced/ basic level), and one test in the general studies battery of tests, sciences and humanities (Britschgi, 2014).

The Finnish National Core Curriculum for Upper Secondary Schools was renewed in 2016, and within the new curriculum, there were some changes regarding mathematics studies. Previously, students had to choose between basic or advanced mathematics before entering upper-secondary school, but now the choice is made during the first year. The purpose of this renewal was to raise students' interest in advanced mathematics by giving some insights during the first year of their studies about advanced mathematics advantages.

\section{Participants}

This study used combined register data, including (1) students who were admitted to Finnish universities during 2013-2015 $(N=46,281)$ and (2) data of students who took the upper-secondary school Matriculation Examination (ME) $(N=93,955)$ during the same years, 2013-2015. This dataset had 46,281 entries representing 
43,639 individual persons, of which 55\% were female. Upper-secondary school graduates are usually 19 years old, but university applicants can be older. Their ages were, however, not available in the register data.

In addition, the participants of this study included students who completed the questionnaire. The questionnaire data was collected with an online survey of firstyear upper-secondary school students. This data represented a total of 1,539 first-year upper-secondary school students from the Oulu area (age 16). Of them, $802 \mathrm{stu}-$ dents responded to the online survey, providing a response rate of $52.1 \%$. The gender distribution of the participants was $40 \%$ male and $60 \%$ female.

\section{Data collection}

The original register data, including all the students admitted to Finnish universities during 2006-2016, was collected from the Finnish universities by CSC, the IT Center for Science Ltd. This study used the data regarding the years $2013-2015(N=46,281)$. The Matriculation Examination data $(N=93,955)$ was collected by the Matriculation Examination Board of Finland.

The questionnaire data $(N=802)$ was collected with the Webropol online survey tool, collecting both quantitative and qualitative data about students' subject choices, future study aspirations, and career plans. The survey was carried out in the spring semester 2017 during school class hours under teacher supervision. In total, the questionnaire included several question points, and this research focused on those questions regarding mathematics choices and study aspirations. These questions were presented in the questionnaire as follows:

1) Please continue the applicable sentences that concern your own choice of mathematics: (openended questions)

I chose advanced mathematics, because...

I did not choose advanced mathematics, because ...

I did not choose basic mathematics, because ...

I chose basic mathematics, because...

2) I am interested in the following study fields:

(Likert scale, $1-5$, from $1=$ not interested to $5=$ very interested)

Arts and Culture

Humanities
Social Sciences

Economics, Administration, Law

Natural Sciences

Information Technology, IT Communication

Technology

Agriculture, Forestry

Medicine

Health and wellbeing

Service Sector

Education

\section{Data analysis}

Register data

Regarding the first and second research questions, the combined register data was examined and the research units concerning students with no corresponding ME results (altogether 8,073 research units) were removed. One part of this missing information stems from uppersecondary school graduates from the years before 2006, when the structure of the examination was different. The data, however, did not contain information on the year when the ME was taken. Students admitted by entrance exam and without completing the ME (e.g., with a background in vocational schools) also belonged to this group.

Altogether 2,563 duplicates (having the same personal ID) were removed from the register data. However, multiple entries on the same student indicating different degree programs were not removed. Since the focus of this study was on student admission, it was important to count every entry to a degree program, regardless of any previous or later choices of the applicant.

\section{Questionnaire data}

Regarding the third and fourth research questions, the questionnaire data $(N=802)$ was based on a cohort sample of 16-year-old upper-secondary school student responses. We investigated what kinds of reasons students gave for choosing basic or advanced mathematics and if there were gender differences in students' mathematics choices.

The analysis of students' reasons began by studying the students' responses given to the open-ended question. After this, thematic categories were formed, and 
each response was individually placed into one of these reason categories, following the Palmer et al. (2017) best-worst Likert scaling (BWS) system. In their study, Palmer et al. used BWS-Choose and BWS-Reject subject selection attribute statement pairs that were grouped as "Advice, Enjoyment and Interest, Logistics, Ability (marks), Subject characteristics, Teaching, and Usefulness." This grouping was adaptable for our analysis, since the original researchers similarly examined the reasons why school students chose and rejected science. In this study, the themes found among students' answers to open-ended questions were thematically categorized into five reason categories: (1) Usefulness (2) Enjoyment and Interest (3) Logistics, (4) Self-efficacy, Ability, and Competence, and (5) Advice, Teaching, and Other. The "subject characteristics" was left out, as we focused only on one subject choice. Within one open-ended response, a student often gave multiple reasons behind his or her mathematics choice, therefore, one response had to be divided into multiple units of analysis. The mutually exclusive reason categories are described in Table 1, along with examples of the students' reasons for choosing or rejecting advanced or basic mathematics.

To examine inter-coder reliability, two independent raters categorized $10 \%$ of the qualitative data. The kappa coefficient of 0.753 (Cohen's kappa) was statistically different from 0 , suggesting that the two independent ratings were largely similar. The reason categories are described in Table 1.

To examine the differences between females and males in reasons for choosing or rejecting advanced and basic mathematics, we used Fisher's exact test, which is similar to the chi-squared ( $\left.\chi^{2}\right)$ test but performs better for imbalanced distributions and distributions with small expected values. Regarding the question about students interest towards the study fields, the Likert-scale responses were analyzed with a t-test to examine similarities of female and male interests.

\section{Results}

The results showed that the student admission process of Finnish universities significantly appreciates advanced mathematics. Only $33 \%$ of the upper-secondary school graduates took the advanced mathematics test in the ME in 2013-2015. The percentage of all students admitted to the universities who took the advanced mathematics test in the ME was 55\%. Furthermore, our data suggests that more than $80 \%$ of the upper-secondary school students/university applicants with advanced mathematics gain admission to the universities. In fact, the first-year university students in our data with advanced mathematics $(25,738)$ represented as much as $83 \%$ of the upper-

Table 1 Examples of students' reasons for choosing or rejecting mathematics

\begin{tabular}{|c|c|c|c|c|}
\hline \multirow{2}{*}{$\begin{array}{l}\text { Reason } \\
\text { categories }\end{array}$} & \multicolumn{2}{|l|}{ Advanced mathematics } & \multicolumn{2}{|l|}{ Basic mathematics } \\
\hline & Choosing & Rejecting & Choosing & Rejecting \\
\hline $\begin{array}{l}\text { Usefulness: } \\
\text { Useful for } \\
\text { future studies, } \\
\text { career, life }\end{array}$ & $\begin{array}{l}\text { It is necessary for } \\
\text { entering my preferred } \\
\text { future study place. Also, } \\
\text { I think in the future it is } \\
\text { needed }\end{array}$ & $\begin{array}{l}\text { Advanced mathematics is not } \\
\text { useful for me and I will not need it } \\
\text { in the future }\end{array}$ & $\begin{array}{l}\text { In basic mathematics there is } \\
\text { enough information for me. I'll get } \\
\text { good grades in basic mathematics } \\
\text { course, so it keeps my study } \\
\text { motivation high }\end{array}$ & $\begin{array}{l}\text { I wanted to enter a good } \\
\text { profession by sc. easy way }\end{array}$ \\
\hline $\begin{array}{l}\text { Advice: Peer, } \\
\text { family, friend, } \\
\text { teacher } \\
\text { advice }\end{array}$ & $\begin{array}{l}\text { Some friends } \\
\text { recommended it and } \\
\text { said it is not that } \\
\text { difficult. And it is not }\end{array}$ & $\begin{array}{l}\text { My student counselor } \\
\text { recommended me to take the basic } \\
\text { mathematics due to my previous } \\
\text { grades }\end{array}$ & [no responses] & $\begin{array}{l}\text { My relatives recommended me } \\
\text { to take the advanced } \\
\text { mathematics courses }\end{array}$ \\
\hline $\begin{array}{l}\text { Enjoyment, } \\
\text { Interest: } \\
\text { Enjoys/ } \\
\text { doesn't enjoy }\end{array}$ & $\begin{array}{l}\text { It appeared like a } \\
\text { challenge worth of } \\
\text { taking. I find } \\
\text { mathematics also a } \\
\text { rewarding subject }\end{array}$ & $\begin{array}{l}\text { I did not find mathematics } \\
\text { interesting, and I did not feel } \\
\text { studying it comfortable or } \\
\text { necessary }\end{array}$ & $\begin{array}{l}\text { During the first course I felt that } \\
\text { things were very difficult, and it is } \\
\text { not worth trying to even start the } \\
\text { advanced mathematics }\end{array}$ & $\begin{array}{l}\text { Because I felt that basic } \\
\text { mathematics might be too easy, } \\
\text { and I want to challenge myself } \\
\text { and take the advanced } \\
\text { mathematics courses }\end{array}$ \\
\hline $\begin{array}{l}\text { Logistics: Fits } \\
\text { better with } \\
\text { students' } \\
\text { study plan or } \\
\text { timetable }\end{array}$ & $\begin{array}{l}\text { I did not want to take } \\
\text { advanced English test, } \\
\text { so I chose advanced } \\
\text { mathematics }\end{array}$ & $\begin{array}{l}\text { I don't have the strength to take } 14 \\
\text { courses of a subject that I did not } \\
\text { find interesting. I'd rather take basic } \\
\text { math, which gives me good grades } \\
\text { and learning is much nicer }\end{array}$ & $\begin{array}{l}\text { It suited my needs better and } \\
\text { gives me more time to better } \\
\text { study those subjects I am } \\
\text { interested in }\end{array}$ & $\begin{array}{l}\text { I wanted to try the advanced } \\
\text { courses first; it is possible to } \\
\text { switch back to basic math } \\
\text { courses if I want }\end{array}$ \\
\hline $\begin{array}{l}\text { Self-efficacy, } \\
\text { Ability, } \\
\text { Competence }\end{array}$ & $\begin{array}{l}\text { I think I am rather good } \\
\text { in mathematics, and I } \\
\text { wanted to learn more }\end{array}$ & $\begin{array}{l}\text { Because I am not good in } \\
\text { mathematics, I would have not } \\
\text { made it in the advanced } \\
\text { mathematics courses }\end{array}$ & $\begin{array}{l}\text { The advanced mathematics would } \\
\text { have been too challenging and } \\
\text { stressful for me }\end{array}$ & $\begin{array}{l}\text { I am good in mathematics, and } \\
\text { short mathematics seemed to } \\
\text { be easy }\end{array}$ \\
\hline $\begin{array}{l}\text { Teaching: } \\
\text { Methods, } \\
\text { style, teacher } \\
\text { likeable or } \\
\text { dislikeable }\end{array}$ & $\begin{array}{l}\text { In our school the } \\
\text { teacher of advanced } \\
\text { mathematics is better } \\
\text { than the teacher of } \\
\text { basic mathematics }\end{array}$ & $\begin{array}{l}\text { The first course seemed difficult, } \\
\text { because the topics were not } \\
\text { explained properly }\end{array}$ & $\begin{array}{l}\text { I didn't like the flipped class } \\
\text { method in the advanced } \\
\text { mathematics }\end{array}$ & $\begin{array}{l}\text { I don't like the basic math } \\
\text { teacher and I wanted to } \\
\text { challenge myself in the } \\
\text { advanced mathematics }\end{array}$ \\
\hline
\end{tabular}


secondary school graduates with advanced mathematics $(30,905)$ during the same 3-year period, 2013-2015.

The significance of advanced mathematics in the different university degree programs can be seen in Fig. 1 and Table 2. Most of the degree programs had higher percentages in advanced mathematics than the overall percentage in the ME (33\%), and all were higher than $23 \%$. This reflects a situation where the needs of the Finnish universities can hardly be met by mathematically skilled upper-secondary school graduates. As seen in Table 2, Medicine, Dentistry, and Veterinary Medicine attracted high numbers of applicants and received high percentages of students with advanced mathematics (90\%, 83\%, and 83\%). However, Technology $(7,095)$ and Natural Sciences $(6,324)$ dominated the student numbers, having also high percentages for advanced mathematics. Either of these numbers was higher than the corresponding numbers for the remaining 18 degreeoffering programs. Humanities and Education have relatively high numbers of students with advanced mathematics, even though the percentages were low, $24 \%$ and $28 \%$, respectively, compared with their totals.

Most of the degree programs were female dominated (Table 2) and so also was the matriculation examination itself, with 59\% females in 2013-2015. While 56\% of all university students were female, university students with advanced mathematics were mostly male with only $44 \%$ being female students. Basic (63\%) and No mathematics
(79\%) were clearly female dominated. In the different university degree programs, Technology had only $22 \%$ female students, Economic Sciences 41\%, and Natural Sciences $45 \%$, whereas most of the other programs were clearly $(>60 \%)$ female dominated.

In Fig. 1, Visual Arts, Theatre, Arts, Musicology, and Dance have been merged into Arts Combined. Of the upper-secondary school graduates, $46 \%$ had taken the basic mathematics test in the ME exam, but in the universities, their percentage was as low as $30 \%$. The highest numbers (Fig. 1) can be seen in Economic Sciences, Education, and Humanities (2,758, 2,572, and 2,396, respectively), which also had high percentages for Basic Math (in Table 2, 40-49\%). Only in Education and Administrative Sciences (49\% and 47\%) were the percentages of Basic Math higher than in the ME exam (46\%). Technology and Medicine were dominated by Advanced Math, and the Basic Math student numbers were very low. Basic Math was female-dominated (64\% female), but in Technology (32\% female), Economic Sciences (42\% female), Science (47\% female), and Physical Education (48\% female), the students with Basic Math in the ME exam were in a majority.

About 21\% of the upper-secondary school graduates in the ME data had not taken a mathematics test at all. The weight of this No Math group was 15\% among the admitted students. This group was $79 \%$ female dominated, which was also reflected in different disciplines

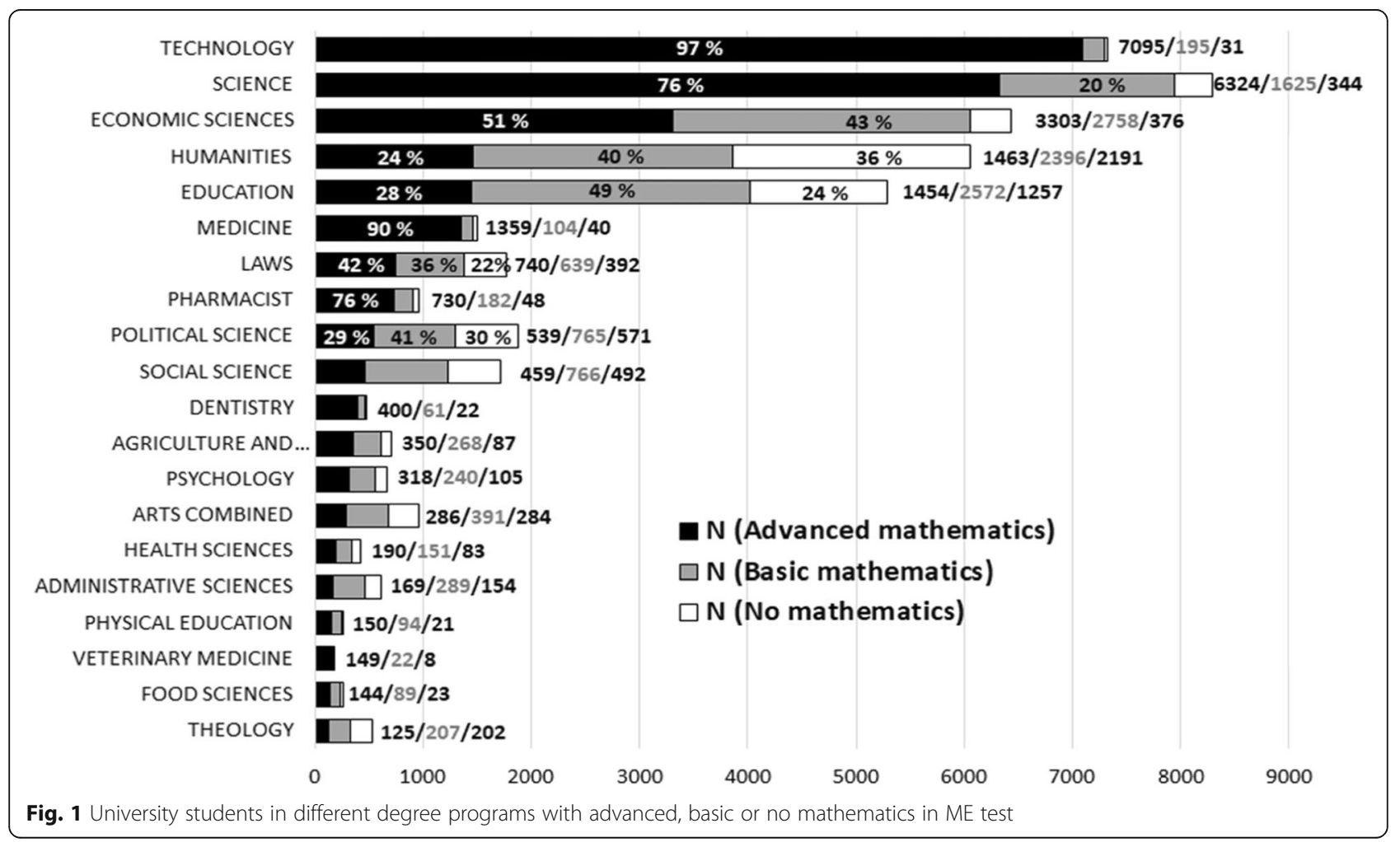


Table 2 Mathematics and gender distribution in different university degree programs 2013-2015

\begin{tabular}{|c|c|c|c|c|c|c|c|c|c|c|c|}
\hline \multirow[t]{2}{*}{ Degree program } & \multicolumn{2}{|l|}{ All } & \multicolumn{3}{|c|}{ Advanced mathematics } & \multicolumn{3}{|c|}{ Basic mathematics } & \multicolumn{3}{|c|}{ No mathematics } \\
\hline & $N$ & $\%$ female & $N$ & $\%$ of all & $\%$ female & $N$ & $\%$ of all & $\%$ female & $N$ & $\%$ of all & $\%$ female \\
\hline Administrative Sciences & 612 & $65 \%$ & 169 & $28 \%$ & $66 \%$ & 289 & $47 \%$ & $59 \%$ & 154 & $25 \%$ & $77 \%$ \\
\hline Agriculture and Forestry & 705 & $56 \%$ & 350 & $50 \%$ & $49 \%$ & 268 & $38 \%$ & $59 \%$ & 87 & $12 \%$ & $79 \%$ \\
\hline Arts combined & 961 & $67 \%$ & 286 & $30 \%$ & $55 \%$ & 391 & $41 \%$ & $67 \%$ & 284 & $30 \%$ & $78 \%$ \\
\hline Dentistry & 483 & $61 \%$ & 400 & $83 \%$ & $61 \%$ & 61 & $13 \%$ & $62 \%$ & 22 & $5 \%$ & $77 \%$ \\
\hline Economic Sciences & 6437 & $41 \%$ & 3303 & $51 \%$ & $38 \%$ & 2758 & $43 \%$ & $42 \%$ & 376 & $6 \%$ & $58 \%$ \\
\hline Education & 5284 & $84 \%$ & 1454 & $28 \%$ & $83 \%$ & 2573 & $49 \%$ & $82 \%$ & 1257 & $24 \%$ & $88 \%$ \\
\hline Food Sciences & 256 & $79 \%$ & 144 & $56 \%$ & $80 \%$ & 89 & $35 \%$ & $73 \%$ & 23 & $9 \%$ & $96 \%$ \\
\hline Health Sciences & 424 & $86 \%$ & 190 & $45 \%$ & $82 \%$ & 151 & $36 \%$ & $86 \%$ & 83 & $20 \%$ & $95 \%$ \\
\hline Humanities & 6050 & $74 \%$ & 1463 & $24 \%$ & $67 \%$ & 2396 & $40 \%$ & $73 \%$ & 2191 & $36 \%$ & $80 \%$ \\
\hline Laws & 1771 & $65 \%$ & 740 & $42 \%$ & $60 \%$ & 639 & $36 \%$ & $64 \%$ & 392 & $22 \%$ & $76 \%$ \\
\hline Medicine & 1503 & $50 \%$ & 1359 & $90 \%$ & $50 \%$ & 104 & $7 \%$ & $53 \%$ & 40 & $3 \%$ & $78 \%$ \\
\hline Pharmacist & 960 & $72 \%$ & 730 & $76 \%$ & $69 \%$ & 182 & $19 \%$ & $77 \%$ & 48 & $5 \%$ & $83 \%$ \\
\hline Physical Education & 265 & $49 \%$ & 150 & $57 \%$ & $49 \%$ & 94 & $35 \%$ & $48 \%$ & 21 & $8 \%$ & $62 \%$ \\
\hline Political Science & 1875 & $63 \%$ & 539 & $29 \%$ & $48 \%$ & 765 & $41 \%$ & $65 \%$ & 571 & $30 \%$ & $75 \%$ \\
\hline Psychology & 663 & $84 \%$ & 317 & $48 \%$ & $81 \%$ & 240 & $36 \%$ & $87 \%$ & 106 & $16 \%$ & $89 \%$ \\
\hline Natural Sciences & 8281 & $45 \%$ & 6315 & $76 \%$ & $43 \%$ & 1622 & $20 \%$ & $47 \%$ & 344 & $4 \%$ & $68 \%$ \\
\hline Social Science & 1717 & $74 \%$ & 459 & $27 \%$ & $66 \%$ & 766 & $45 \%$ & $70 \%$ & 492 & $29 \%$ & $87 \%$ \\
\hline Technology & 7321 & $22 \%$ & 7095 & $97 \%$ & $21 \%$ & 195 & $3 \%$ & $32 \%$ & 31 & $0 \%$ & $48 \%$ \\
\hline Theology & 534 & $60 \%$ & 125 & $23 \%$ & $43 \%$ & 207 & $39 \%$ & $58 \%$ & 202 & $38 \%$ & $72 \%$ \\
\hline Vet. medicine & 179 & $90 \%$ & 149 & $83 \%$ & $89 \%$ & 22 & $12 \%$ & $95 \%$ & 8 & $4 \%$ & $100 \%$ \\
\hline In total & 46,281 & $56 \%$ & 25,737 & $56 \%$ & $44 \%$ & 13,812 & $30 \%$ & $63 \%$ & 6732 & $15 \%$ & $79 \%$ \\
\hline
\end{tabular}

(Table 2). Understandably, there were some degree programs, like Technology (31 out of 7,321), where the number of No Math students was very low. The No Math students were relatively abundant in Education (24\%), which was also a highly female-dominated degree program $(84 \%)$. This may reflect low motivation or even a dislike for mathematics among education students, most of whom become teachers at different school and early childhood education levels. There is no evident reason for high No Math numbers in Political Science (30\%), Social Science (29\%), and Administrative Science (25\%).

The third research question addresses what kinds of reasons students gave for choosing basic or advanced mathematics based on the qualitative data from the survey. In total, 1,601 answers were given to the openended questions. Their distribution in the reason categories based on choosing or rejecting advanced or basic mathematics is presented in Table 3 .

According to the students' responses, the main reason for choosing advanced mathematics was its usefulness $(N=359)$. Many students replied that they believed Advanced Math opens more options for their future professions or places of study, although during the first semester of upper-secondary school, many did not have a clear view of their future studies or career plans. Those who had a clear career plan towards fields that demand advanced mathematics skills were clearly aware of the usefulness of the subject. For example, "I assume that by studying it [Advanced Math] I will have a better chance to enter the professions that are better paid. I also know that I need it to enter medical school" and "I don't know my future profession, so I chose advanced mathematics as I don't want to rule out any options." Another reason for choosing advanced math was enjoyment and interest $(N=119)$. Those who enjoyed mathematics wanted to practice more. Many students reported that they wanted to challenge themselves and that solving problems was enjoyable. For example, "I enjoy mathematics and want to challenge myself with it" and "I want to learn more mathematics and accept new challenges, and I enjoy solving problems." The third most named reason for choosing advanced mathematics was self-efficacy, ability, and competence $(N=54)$. Many found that they had skills and competences in mathematics, and during their previous studies, they had received good marks in mathematics. For example, "I want to learn mathematics as much as possible, as I am skilled in it" and "I have previously received good marks in mathematics."

Among the upper-secondary school students in Oulu, only a very few students mentioned advice from parents 
Table 3 The upper-secondary school students' reasons for choosing or rejecting mathematics

\begin{tabular}{|c|c|c|c|c|c|c|c|c|c|c|c|c|}
\hline \multirow{3}{*}{ Reason categories } & \multicolumn{6}{|c|}{ Advanced mathematics } & \multicolumn{6}{|c|}{ Basic mathematics } \\
\hline & \multicolumn{3}{|c|}{ Choosing } & \multicolumn{3}{|l|}{ Rejecting } & \multicolumn{3}{|c|}{ Choosing } & \multicolumn{3}{|c|}{ Rejecting } \\
\hline & Female & Male & Total & Female & Male & Total & Female & Male & Total & Female & Male & Total \\
\hline Usefulness & 216 & 143 & 359 & 42 & 16 & 58 & 23 & 12 & 35 & 133 & 98 & 231 \\
\hline Enjoyment, interest & 67 & 52 & 119 & 127 & 4 & 131 & 39 & 3 & 42 & 53 & 21 & 74 \\
\hline Logistics & 13 & 2 & 15 & 12 & 4 & 16 & 13 & 2 & 15 & 14 & 17 & 31 \\
\hline Self-efficacy, ability, competence & 32 & 22 & 54 & 93 & 45 & 138 & 79 & 32 & 111 & 45 & 40 & 85 \\
\hline Advice, teaching, other & 12 & 13 & 25 & 5 & 13 & 18 & 12 & 11 & 23 & 10 & 11 & 21 \\
\hline Total & 340 & 232 & 572 & 279 & 82 & 361 & 166 & 60 & 226 & 255 & 187 & 442 \\
\hline
\end{tabular}

or peers or teaching style or quality as important factors when choosing advanced mathematics.

Some students described rejecting advanced mathematics $(N=58)$ because they did not find the subject necessary or useful for their future field of study or work. Particularly, females $(N=93)$ versus males $(N=45)$ responded that they rejected advanced mathematics for a lack of interest and competence. The most reported reason for choosing basic mathematics $(N=111)$ was self-efficacy, ability, and competence, and many of these respondents reported they did not feel they were "able to make it" in the advanced mathematics course.

Students often explained rejecting basic mathematics $(N=231)$ with reasons similar to those for choosing advanced mathematics; they wanted to keep more study and career options open by selecting advanced mathematics.

When we compared female and male responses, there were evident differences in between the two. Females reported more reasons $(N=127)$ than males $(N=4)$ related to enjoyment and interest for rejecting advanced mathematics and self-efficacy, ability, and competence (females, $N=93$; males, $N=45$ ). The same pattern was also evident in the responses for choosing basic mathematics.

Regarding the reasons for upper-secondary school students choosing or rejecting mathematics, we used Fisher's exact test for finding out if there were genderrelated differences. Fisher's exact test (two-way) indicated that there were no significant gender-related differences in reasons for choosing advanced mathematics ( $p=$ 0.153). However, regarding rejecting advanced mathematics $(p<0.001)$, choosing basic mathematics $(p<0.01)$, and rejecting basic mathematics $(p<0.05)$, the Fisher's test indicated that there were significant gender-related differences in the reasons students provided for their choices.

Finally, students rated their interest in the provided study fields (see Table 4). In the questionnaire, students were asked to rate their interest towards the study fields of higher education on a scale of 1-5. Health and wellbeing, Humanities Service Sector, Education, and Arts and Culture attracted more females than males.
Assessing with the t-test, we found statistically significant differences regarding every field of study. Especially, in terms of Information Technology/IT Communication and Technology, females indicated significantly less interest towards these fields compared to males. Vice versa, towards Health and wellbeing and Education study fields, males had significantly less interest.

\section{Discussion}

Regarding the question of how students' mathematics choice affects their admission to university degree programs, it is evident that the choice of mathematics appears as a significant divider of Finnish students' educational pathways. Secondary school graduates who completed the advanced mathematics test had very good chances to be admitted to the universities. About $83 \%$ of the secondary school graduates who completed the advanced mathematics test were eventually admitted to the universities in 2013-2015. This can be concluded by direct comparison of the numbers of advanced mathematics in the register data (an annual average of 8,926) and the matriculation examination data (an annual average 10,302). Effectively, $83 \%$ was very close to all, since our data did not represent all the new students in the universities during those years, and many secondary school graduates were also aiming to study at the universities of applied sciences. All the degree programs appreciated mathematical skills, and some of them had problems with student admissions. These problems were especially related to Technology and Science, where the need for mathematical skills was very high.

Regarding the students' reasons behind their mathematics choices between basic or advanced, there were some differences between female and male respondents and their given reasons. Compared to males, females often reported lack of self-efficacy, ability, and competence towards mathematics studies as reasons for not selecting advanced mathematics, corresponding to the findings of several prior studies (Ceci \& Williams, 2007; Dasgupta \& Stout, 2014; Hübner et al., 2017; Stage \& Maple, 1996). Nonetheless, the majority of both genders 
Table 4 Students' interest towards study fields

\begin{tabular}{|c|c|c|c|c|c|}
\hline \multirow[t]{3}{*}{ Study field } & \multicolumn{4}{|c|}{ Interest } & \multirow[b]{3}{*}{$t(d f=792)$} \\
\hline & \multicolumn{2}{|l|}{ Male } & \multicolumn{2}{|c|}{ Female } & \\
\hline & M & $S D$ & M & SD & \\
\hline Arts and Culture & 2.09 & 1.22 & 2.52 & 1.39 & $-4.52^{* * *}$ \\
\hline Humanities & 2.63 & 1.14 & 3.08 & 1.18 & $-5.38^{* * *}$ \\
\hline Social Sciences & 2.89 & 1.15 & 2.65 & 1.22 & $2.81^{* *}$ \\
\hline Economics, Administration, Law & 3.13 & 1.17 & 2.75 & 1.34 & $4.29 * * *$ \\
\hline Natural Sciences & 3.00 & 1.22 & 2.69 & 1.32 & $3.39 * *$ \\
\hline Information Technology, IT Communication & 2.96 & 1.13 & 1.82 & .98 & $15.07^{* * *}$ \\
\hline Technology & 3.23 & 1.22 & 1.75 & 1.03 & $17.68^{* * *}$ \\
\hline Agriculture, Forestry & 2.18 & 1.07 & 1.49 & .83 & $9.54^{* * *}$ \\
\hline Medicine & 2.98 & 1.34 & 3.18 & 1.43 & $-2.05^{*}$ \\
\hline Health and wellbeing & 2.76 & 1.17 & 3.49 & 1.23 & $-8.19^{* * *}$ \\
\hline Service sector & 2.48 & 1.09 & 2.96 & 1.16 & $-5.79 * * *$ \\
\hline Education & 2.20 & 1.07 & 2.93 & 1.22 & $-8.65^{* * *}$ \\
\hline
\end{tabular}

$p<0.05 ;{ }^{* *} p<0.01 ;{ }^{* * *} p<0.001$

acknowledged the value of the subject at the age of 16 , during their first year of studies in upper-secondary school. However, many of these students tended to move to basic mathematics studies during the ensuing 2-3 years. Among students taking part in the online survey, as many as $65 \%$ selected advanced mathematics during the first years but were already hesitating: "I want to try it [advanced mathematics] out first" and "It is possible to drop out from advanced and go to basic mathematics." Indeed, moving from challenging, time-consuming advanced mathematics (14 courses) to basics (9 courses) was more likely than the other way around.

This study shows that gender differences were especially significant in students' interest towards different fields of study. In the cohort sample, males were interested in Information Technology, IT Communication, and Technology but showed less interest towards Health and Wellbeing and Education than their female counterparts. This result is in line with a previous study ( $\mathrm{Su}$ et al., 2009) that found men prefer working with things and women prefer working with people, also raising questions about STEM identity as studied by Seyranian et al. (2018).

On the limitations of this study, from the register data, we were able to investigate only the issues regarding students' gender. The qualitative data might be somewhat influenced by respondents' gender; males tended to provide shorter responses compared to the females. In future studies, these factors may need to be also considered.

\section{Conclusions}

The current study investigated the connection between STEM subject choice, especially the choice of mathematics, conducted in upper-secondary school and their relation to university admissions. Further, we examined the gender distribution in different university degree programs from the perspective of the mathematics choice for finding out in which programs students with advanced, basic, or no mathematics end up within the universities. Next, we analyzed the large dataset to explore what is the gender distribution in different university degree programs covering all the universities in Finland. Finally, for finding out the students' reasons behind the mathematics choices, we collected a cohort sample of 802 students from upper-secondary schools to investigate the students' interest in different fields of study to establish the existing gender differences in them.

These results show that advanced mathematics was highly valued in Finnish universities. According to our cohort sample, the majority of students that chose studies in advanced mathematics believed in its usefulness for their future studies or career. Yet, although the Finnish girls were the topmost mathematics performers in the world (Ministry of Education and Culture, 2016), we found that their further study interests were significantly segregated by gender, neglecting the vast possibilities of STEM careers. Adding to the STEM identity and gender study findings of Seyranian et al. (2018), careful attention must be paid to students' physical and social learning environments which may send cues about who belongs in or may succeed in STEM fields.

The foundation for mathematics and interest towards STEM is built during the early years of education. Blotnicky, Franz-Odendaal, French, and Joy (2018) have recognized a need to improve access to knowledge which facilitates students' understanding of STEM careers and the nature of STEM work. According to Cannady et al. (2017), one-size-fits-all policies for broadening 
participation in the STEM workforce are unlikely to be successful, but programs that are designed to generate wonder and fascination with STEM content may be successful in attracting more girls (Cannady et al., 2017).

Recently, research has focused on identifying the biological and sociocultural factors for the divergence in gender abilities, interests, and career choices. Wang and Degol (2016) concluded that for reducing the gender gap in STEM, attention should be given to address the contributory cognitive, motivational, and sociocultural factors, primarily by maximizing the number of career options that women perceive as attainable and compatible with their abilities, preferences, and goals. Otherwise, large numbers of mathematically talented females will continue to slip through the cracks when their choices are restricted by cultural barriers, gender stereotypes, or misinformation.

In Finland, students make subject choices that can decisively affect their futures at the age of 16 or even earlier. Therefore, it would be essential to seek new, more effective means and ways to deliver information during their early years about relatively new careers such as ICT (Information and communication technologies). As social cognitive career theory (Lent et al., 1994) suggests, career interest, choice, and personal goals form a complex human agency process that includes performance, self-efficacy, and outcome expectations. Further, Seyranian et al. (2018) studied interventions that strengthen STEM identification for women and suggested that these interventions may signal one promising approach to reduce gender disparities. Currently, in Oulu, new STEM learning environments are evolving in close cooperation with educators and ICT companies. It is important to discover if these types of new learning environments, out-of-school time science activities (Dabney et al. 2012), or carefully structured STEM interventions can actually help girls' STEM identities to flourish and spark boys' interests towards STEM subjects. We suggest further research to find out if such actions can provide effective ways to motivate youth towards STEM pathways and subjects and also to help them see the constantly evolving possibilities of future STEM careers.

\footnotetext{
Abbreviations

BWS: Best-worst scalingICTInformation and communication technologyMEMatriculation examinationOECDOrganization for Economic Cooperation and DevelopmentPISAThe Program for International Student AssessmentSTEMScience, technology, engineering, and mathematics

\section{Acknowledgements}

The authors thank the students, student counselors, teachers, and principals of Oulu upper secondary schools, also the staff of the Department of Education and culture of Oulu, for giving their time and support for this study. We are grateful to the Matriculation Examination Board and the CSC for opening their student registers for this research. We also owe a debt of gratitude to every Finnish research university that kindly supported our research by giving us their student selection information for research purposes.
}

\section{Authors' contributions}

Satu Kaleva collected the cohort sample, carried out the analysis and drafted the manuscript together with Hanni Muukkonen and Jouni Pursiainen. Jouni Pursiainen and Jarmo Rusanen collected the register datasets, Mirkka Hakola and Jouni Pursiainen analyzed the data and Jouni Pursiainen contributed on writing the data analysis of the quantitative data. Hanni Muukkonen and Jouni Pursiainen provided feedback on the full manuscript and participated in the study's conceptualization, design, and coordination conducted by Satu Kaleva. All writers have approved the final manuscript.

\section{Authors' information}

Satu Kaleva is a doctoral student at the University of Oulu in the Department of Education. She has worked for several years in the development projects of education, and her research interest is on developing educational pathways for improving gender and socio-economic equity in STEM fields, and in school and work life cooperation for enhancing students' future skills. Jouni Pursiainen is professor in Chemistry in Oulu University also leads the STEM center of Oulu University. He is interested in the study paths from upper secondary school to the universities, especially the effect of subject choices in the matriculation examination.

Mirkka Hakola is a full time Release Manager at Empower IM but also a graduate student at the University of Oulu in the Department of Chemistry. Her master theses research concentrated in finding the background factors that are influencing student acceptance process. She has participated in the development projects of education.

Jarmo Rusanen is a professor emeritus, geoinformatics, at the Geography Research Unit, University of Oulu. His research has been focused always on register based data, like matriculation examination in this study.

Hanni Muukkonen is Professor in Educational Psychology at the University of Oulu, Finland. Her research areas include collaborative learning, knowledge creation, learning analytics and methodological development. To study learning processes and pedagogical design, she has been involved in and lead several large scale international educational technology development projects carried out in multidisciplinary collaboration.

\section{Funding}

The authors are grateful for receiving funding for this research from the University of Oulu, the Adult Education Allowance of Finland, and from the Oulu University project regarding student admissions, funded by the Ministry of Education and Culture

\section{Availability of data and materials}

The questionnaire data were collected mostly from minor aged (16-17-yearold) students with consent of confidentiality and therefore cannot be shared. The register datasets were provided to the University of Oulu for research purposes under strict condition of not sharing them without permission from the CSC, the other Finnish Universities involved, as well as the Matriculation Examination Board. For further information about the availability of the register data, please contact the corresponding author.

\section{Ethics approval and consent to participate}

This research was approved by the City of Oulu Department of Education and Culture. All students in this study provided consent prior to study participation.

\section{Consent for publication}

Not applicable.

\section{Competing interests}

The authors had no competing interests.

Received: 20 June 2019 Accepted: 14 November 2019 1.

\section{References}

Allen, C. D., \& Eisenhart, M. (2017). Fighting for desired versions of a future self: How young women negotiated STEM-related identities in the discursive landscape of educational opportunity. Journal of the Learning Sciences, 26(3), 407-436 Retrieved from https://doi.org/10.1080/10508406.2017.1294985.

Bandura, A. (1986). Social foundations of thought and action: A social cognitive theory. Englewood Cliffs, NJ: Prentice-Hall. 
Bilbao-Osorio, B., Dutta, S., \& Lanvin, B. (Eds.). (2014). The global information technology report, 2014 Retrieved from https://core.ac.uk/download/pdf/30673033.pdf.

Blotnicky, K. A., Franz-Odendaal, T., French, F., \& Joy, P. (2018). A study of the correlation between STEM career knowledge, mathematics self-efficacy, career interests, and career activities on the likelihood of pursuing a STEM career among middle school students. International journal of STEM education, 5(1), 22 https://doi.org/10.1186/s40594-018-0118-3.

Bottia, M., Stearns, E., Mickelson, R., Moller, S., \& Valentino, L. (2015). Growing the roots of STEM majors: Female math and science high school faculty and the participation of students in STEM. Economics of Education Review, 45, 14-27. https://doi.org/10.1016/j.econedurev.2015.01.002.

Britschgi, V. (2014). The Finnish Matriculation Examination. The Board of Finnish ME: Ylioppilastutkintolautakunta Retrieved from https://www. ylioppilastutkinto.fi/images/sivuston_tiedostot/Kehittaminen/YTL_ presentation_English.pdf.

Cannady, M., Moore, D., Votruba-Drzal, E., Greenwald, E., Stites, R., \& Schunn, C. D. (2017). How personal, behavioral, and environmental factors predict working in STEMM vs non-STEMM middle-skill careers. International Journal of STEM Education, 4(22) https://doi.org/10.1186/s40594-017-0079-y.

Castaño, C., \& Webster, J. (2011). Understanding women's presence in ICT: The life course perspective. International Journal of Gender, Science and Technology, 3(2), 364-386 Retrieved from http://genderandset.open.ac.uk/ index.php/genderandset/article/view/168/333.

Ceci, S. J., \& Williams, W. M. (Eds.). (2007). Why aren't more women in science? Top researchers debate the evidence. Washington, DC: American Psychological Association Retrieved from http://scripts.cac.psu.edu/dept/cls/pubs/affiliated/ valian/2006WomenAtTheTopInScience.pdf.

Chow, A., Eccles, J., \& Salmela-Aro, K. (2012). Task value profiles across subjects and aspirations to physical and IT-related sciences in the United States and Finland. Developmental Psychology, 48(6), 1612-1628 Retrieved from https:// psycnet.apa.org/doi/10.1037/a0030194.

Dabney, K. P., Tai, R. H., Almarode, J. T., Miller-Friedmann, J. L., Sonnert, G., Sadler, P. M., \& Hazari, Z. (2012). Out-of-school time science activities and their association with career interest in STEM. International Journal of Science Education, Part B, 2(1), 63-79. DOI: https://doi.org/10.1080/21548455.2011.629455

Dasgupta, N., \& Stout, J. G. (2014). Girls and women in science, technology, engineering, and mathematics: STEMing the tide and broadening participation in STEM careers. Policy Insights from the Behavioral and Brain Sciences, 1(1), 21-29 Retrieved from https:/journals.sagepub.com/doi/pdf/10.1177/2372732214549471.

European Commission (2019). The Digital Economy and Society Index (DES), retreived from https:/ec.europa.eu/digital-single-market/en/desi

Finland, S. (2017). Finland in Figures, 2017 Retrieved from http:/tilastokeskus.fi/ tup/suoluk/index_en.html.

Finnish Government (2019) Agreement on the New Government Programme of Finland. Retrieved from https://valtioneuvosto.fi/hallitusneuvottelut

Finnish Ministry of Education and Culture (2017). The Finnish education in a nutshell. Retrieved from file:///C:/Users/skaattar/Downloads/finnish-education-in-nutshell.pdf

Holland, J. L. (1997). Making vocational choices: A theory of vocational personalities and work environments (3rd ed.). Odessa, FL: Psychological Assessment Resources.

Hübner, N., Wille, E., Cambria, J., Oschatz, K, Nagengast, B., \& Trautwein, U. (2017). Maximizing gender equality by minimizing course choice options? Effects of obligatory coursework in math on gender differences in STEM. Journal of Educational Psychology, 109(7), 993 Retrieved from https://doi.org/10.1037/edu0000183.

Jang, H. (2016). Identifying 21st century STEM competencies using workplace data. Journal of Science Education and Technology, 25(2), 284-301.pp 284-30. Retrieved from https://doi.org/10.1007/s10956-015-9593-1

Lent, R. W., Brown, S. D., \& Hackett, G. (1994). Toward a unifying social cognitive theory of career and academic interest, choice, and performance. Journal of Vocational Behavior, 45(1), 79-122 Retrieved from https://doi.org/10.1006/ivbe.1994.1027.

Linnansaari, J., Viljaranta, J., Lavonen, J., Schneider, B., \& Salmela-Aro, K. (2015). Finnish students' engagement in science lessons. NorDiNa: Nordic Studies in Science Education, 11(2), 192-206 Retrieved from https://www.journals.uio.no/ index.php/nordina/article/view/2047.

Lin-Siegler, X., Ahn, J. N., Chen, J., Fang, F. F. A., \& Luna-Lucero, M. (2016). Even Einstein struggled: Effects of learning about great scientists' struggles on high school students' motivation to learn science. Journal of Educational Psychology, 108(3), 314 Retrieved from https://doi.org/10.1037/edu0000092.

Margot, K. C., \& Kettler, T. (2019). Teachers' perception of STEM integration and education: A systematic literature review. International Journal of STEM Education, 6(1), 2 Retrieved from https://doi.org/10.1186/s40594-018-0151-2.
Ministry of Education and Culture (2016). PISA 2015: Finnish youth still at the top despite the drop [Press release]. Retrieved from https://ktl.jyu.fi/en/ pressreleases/press-releases-2004/t061216

Ministry of Education and Culture (2017). Finnish education system. Retrieved from http://minedu.fi/en/education-system

Osborne, J., Simon, S., \& Collins, S. (2003). Attitude towards science: A review of the literature and its implications. International Journal of Science Education 25(9), 1049-1079 Retrieved from https://www.tandfonline.com/doi/abs/10.1 080/0950069032000032199.

Pajares, F., \& Miller, M. D. (1994). Role of self-efficacy and self-concept beliefs in mathematical problem solving: A path analysis. Journal of Educational Psychology, 86(2), 193-203 Retrieved from https://doi.org/10.1037/0022-0663.86.2.193.

Pajares, F., \& Urdan, T. C. (2006). Self-efficacy beliefs of adolescents. Greenwich, CT: Information Age Publishing.

Palmer, T. A., Burke, P. F., \& Aubusson, P. (2017). Why school students choose and reject science: A study of the factors that students consider when selecting subjects. International Journal of Science Education, 39(6), 645-662 Retrieved from https://www.tandfonline.com/doi/abs/10.1080/09500693.2017.1299949.

Parker, P., Marsh, H., Ciarrochi, J., Marshall, S., \& Abduljabbar, A. (2014). Juxtaposing math self-efficacy and self-concept as predictors of long-term achievement outcomes. Educational Psychology, 34(1), 29-48 Retrieved from https://doi.org/10.1080/01443410.2013.797339.

Perez, T., Cromley, J., \& Kaplan, A. (2014). The role of identity development, values, and costs in college STEM retention. Journal of Educational Psychology, 106(1), 315-329 Retrieved from https://psycnet.apa.org/ doiLanding?doi=10.1037/a0034027.

Seyranian, V., Madva, A., Duong, N., Abramzon, N., Tibbetts, Y., \& Harackiewicz, J. M. (2018). The longitudinal effects of STEM identity and gender on flourishing and achievement in college physics. International Journal of STEM Education, 5(1), 40 Retrieved from https://doi.org/10.1186/s40594-018-0137-0.

Slavit, D., Nelson, T. H., \& Lesseig, K. (2016). The teachers' role in developing, opening, and nurturing an inclusive STEM-focused school. International Journal of STEM Education, 3(1), 7 Retrieved from https://doi.org/10.1186/ s40594-016-0040-5.

Stage, F., \& Maple, S. (1996). Incompatible goals: Narratives of graduate women in the mathematics pipeline. American Educational Research Journal, 33(1), 2351 Retrieved from http://www.jstor.org/stable/1163379.

Su, R., Rounds, J., \& Armstrong, P. I. (2009). Men and things, women and people: A meta-analysis of sex differences in interests. Psychological Bulletin, 135(6), 859 Retrieved from https://doi.org/10.1037/a0017364.

Välijäni J., \& Sulkunen S. (2016). Finnish school in international comparison. In H. Niemi, A. Toom, \& A. Kallioniemi (Eds.) Miracle of Education (pp. 3-21). Rotterdam, Netherlands: Sense Publishers. https://doi.org/10.1007/978-94-6300-776-4_1

Vincent-Ruz, P., \& Schunn, C. D. (2018). The nature of science identity and its role as the driver of student choices. International Journal of STEM Education, 5(1), 48 Retrieved from https://doi.org/10.1186/s40594-018-0140-5.

Wang, M., \& Degol, J. (2016). Gender gap in science, technology, engineering, and mathematics (STEM): Current knowledge, implications for practice, policy, and future directions. Educational Psychology Review, 29(1), 119-140 Retrieved from https://ink.springer.com/content/pdf/10.1007/s10648-015-9355-x.pdf.

Wang, M. T., \& Degol, J. (2013). Motivational pathways to STEM career choices: Using expectancy-value perspective to understand individual and gender differences in STEM fields. Developmental Review, 33(4), 304-340 Retrieved from https://doi.org/10.1016/j.dr.2013.08.001.

Wang, M. T., Eccles, J. S., \& Kenny, S. (2013). Not lack of ability but more choice: Individual and gender differences in choice of careers in science, technology, engineering, and mathematics. Psychological Science, 24(5), 770-775 Retrieved from https://doi.org/10.1177\%2F0956797612458937.

Williams, C., Stanisstrect, M., Spall, K., Boyes, E., \& Dickson, D. (2003). Why aren't secondary students interested in physics? Physics Education, 38(4), 324-329.

Wu, X., Deshler, J. M., \& Fuller, E. (2018). The effects of different versions of a gateway STEM course on student attitudes and beliefs. International Journal of STEM Education., 5(44). https://doi.org/10.1186/s40594-018-0141-4.

Zeldin, A., \& Pajares, F. (2000). Against the odds: Self-efficacy beliefs of women in mathematical, scientific, and technological careers. American Educational Research Journal, 37(1), 215-246. https://doi.org/10.3102/00028312037001215.

\section{Publisher's Note}

Springer Nature remains neutral with regard to jurisdictional claims in published maps and institutional affiliations. 